\title{
An Approach to Enhance Specificity Against RNA targets Using Hetero Conjugates of Aminoglycosides and Chloramphenicol (or Linezolid)
}

Jongkook Lee, Miyun Kwon, Kyung Hyun Lee, Sunjoo Jeong, ${ }^{1}$ Soonsil Hyun, Kye Jung Shin and Jaehoon Yu*

Life Science Division, Korea Institute of Science \& Technology, P.O. Box 131 Cheongryang, Seoul 130-650, Korea

Department of Molecular Biology, College of Natural Sciences, Dankook University, Seoul 140-714, Korea

*To whom the correspondence should be addressed.

e-mail) jhoonyu@kist.re.kr

\section{Supporting Information:}

1. Scheme S1. Synthesis of NC1 (3a), NC2 (3b), and NC3 (3c).

2. Scheme S2. Synthesis of chloramphenicol moiety.

3. Scheme S3. Synthesis of NL (14).

4. Experimental procedures and characterizations of conjugates and their synthetic intermediates.

5. Experimental procedures for affinity measurement between RNA and compounds using fluorescence anisotropy.

6. Table S1. Binding affinities $(\mathrm{Kd})$ of conjugates to various RNA targets.

7. Table S2. Binding affinities $(\mathrm{Kd})$ of conjugates to mutant RNA targets.

8. Experimental procedures and data for enzymatic foot printing of RNA.

1 Dankook University 
Scheme S1. Synthesis of NC1 (3a), NC2 (3b), and NC3 (3c).

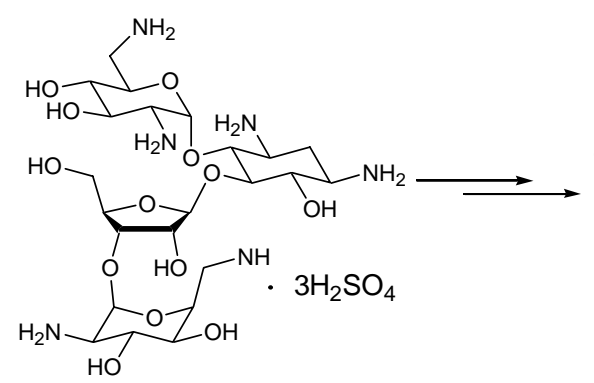

Neomycin (1) Sulfate

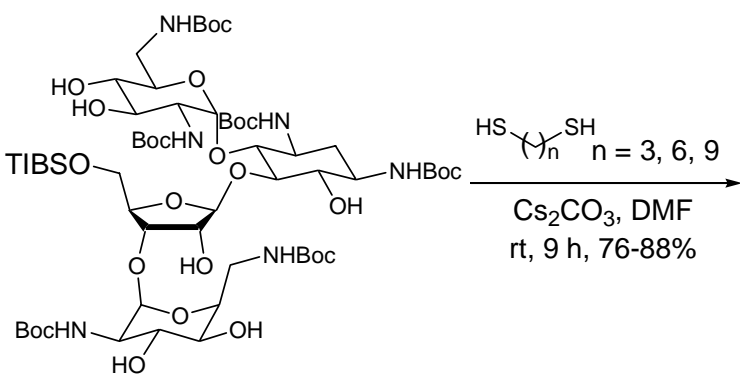

4

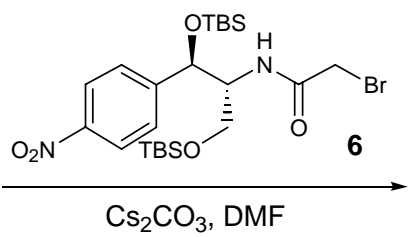

rt $\sim 60{ }^{\circ} \mathrm{C}, 8 \mathrm{~h} \sim 72 \mathrm{~h}$ $32-87 \%$

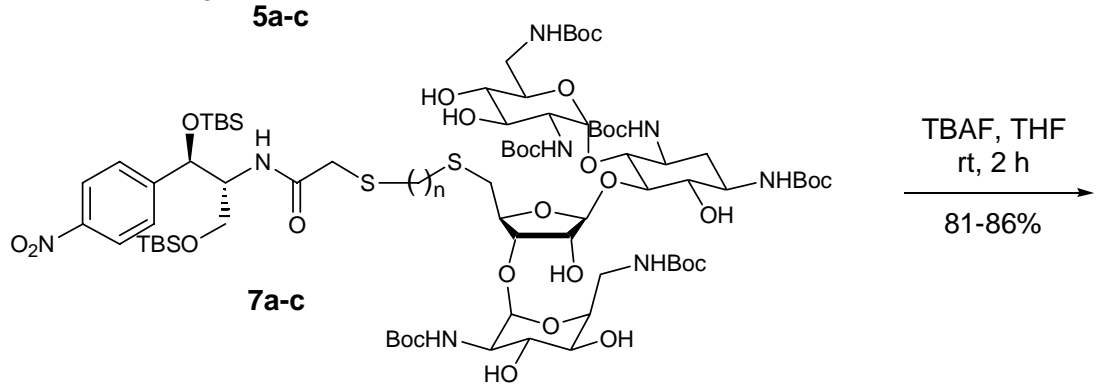

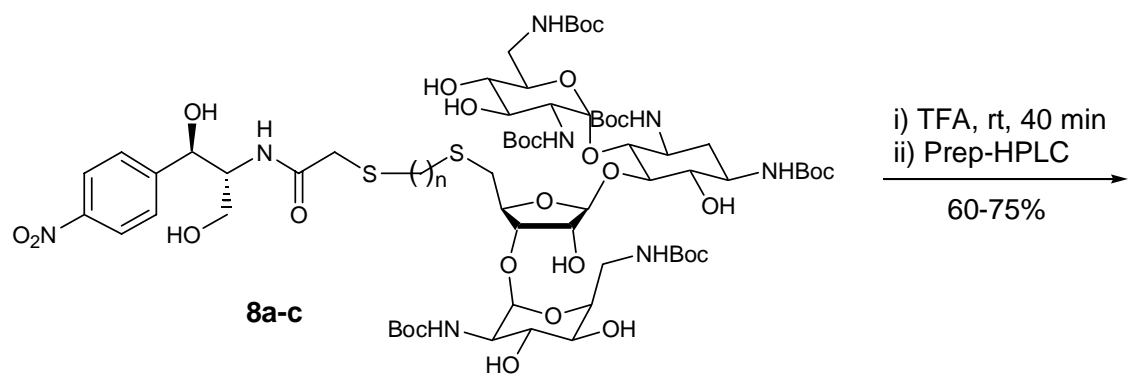

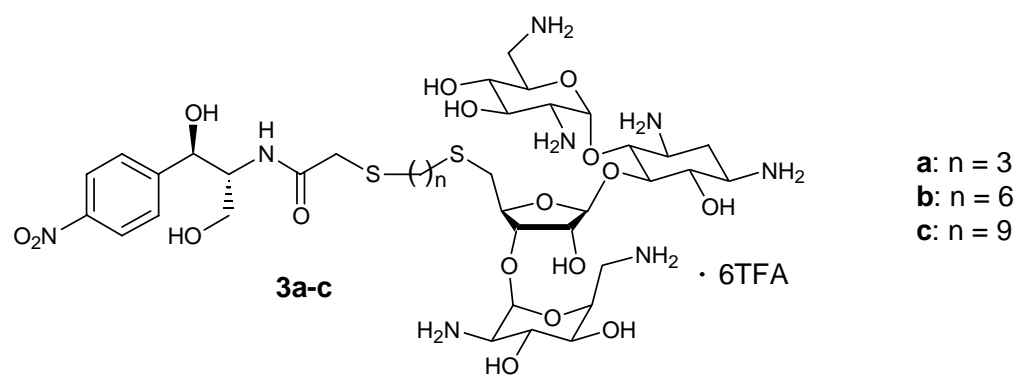


1. Scheme S2. Synthesis of chloramphenicol moiety.

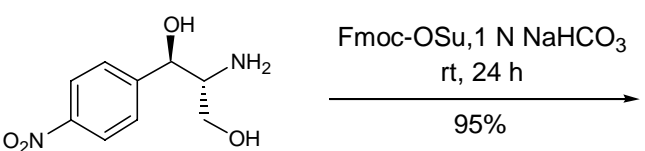

9

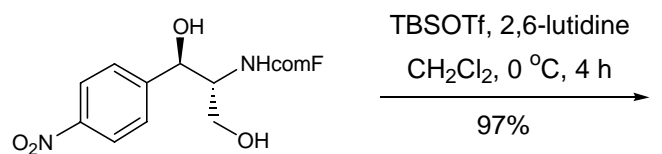

10

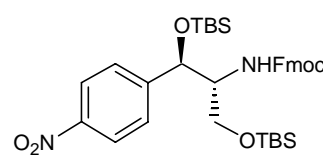

11

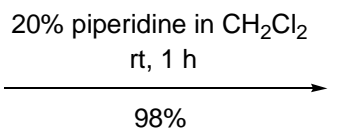

$98 \%$

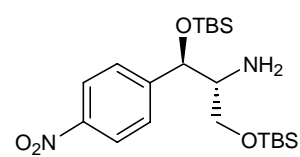

12

$$
\begin{gathered}
\begin{array}{c}
\text { bromoacetyl bromide } \\
\text { pyridine, } \mathrm{CH}_{2} \mathrm{Cl}_{2} \\
0{ }^{\circ} \mathrm{C}, 1 \mathrm{~h}
\end{array} \\
\hline 95 \%
\end{gathered}
$$

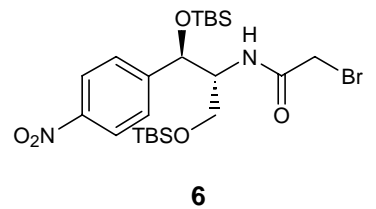


3. Scheme S3. Synthesis of NL (14).
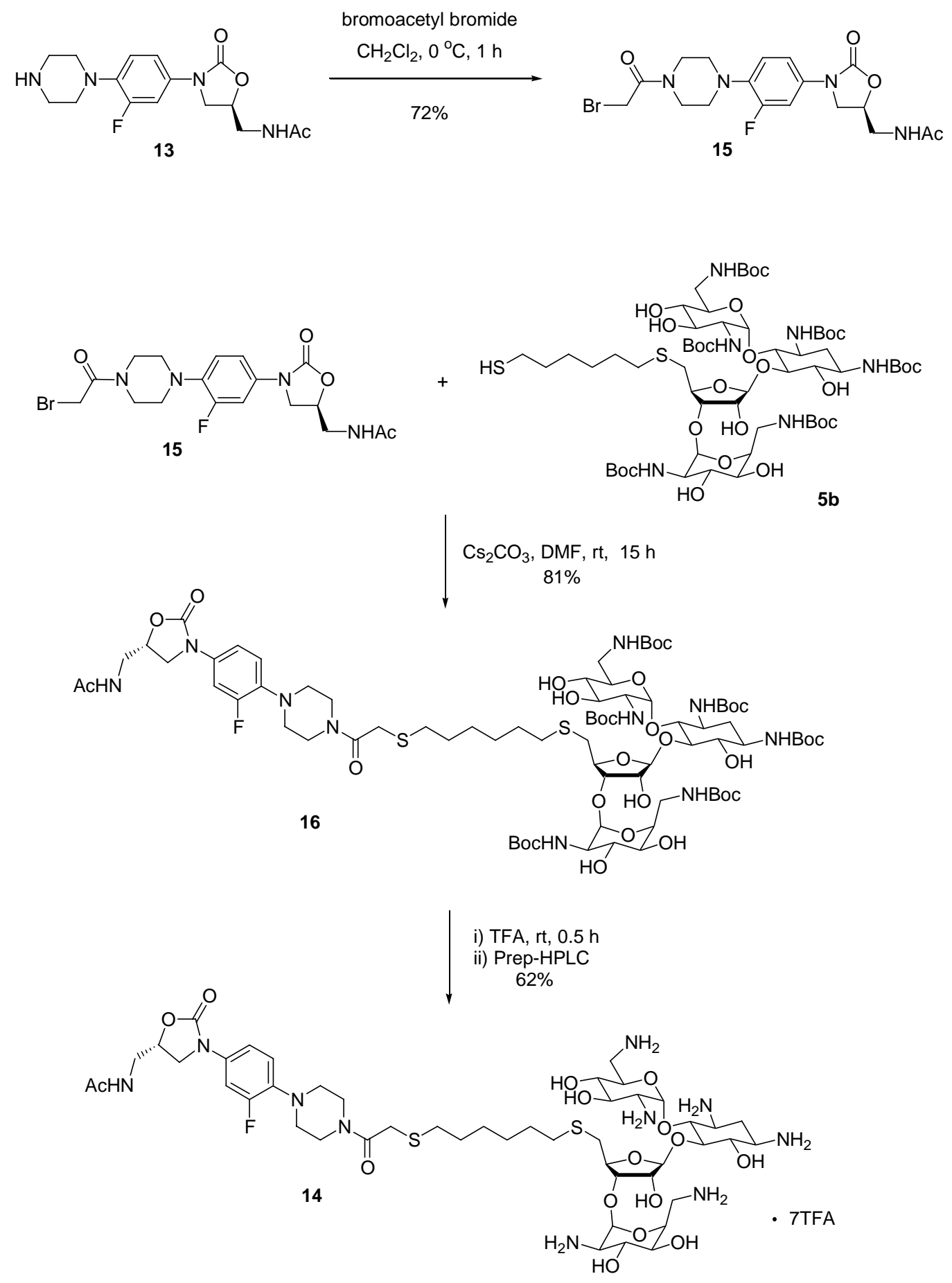
4. Experimental procedures and characterizations of conjugates and their synthetic intermediates.

Compound $5 \boldsymbol{a}$ To a solution of sulfonate $4(880 \mathrm{mg}, 0.59 \mathrm{mmol})$ in DMF $(11.8 \mathrm{~mL})$ were added 1,3-propanedithiol (0.47 mL, $4.68 \mathrm{mmol})$ and $\mathrm{Cs}_{2} \mathrm{CO}_{3}(364 \mathrm{mg}, 1.12 \mathrm{mmol})$ at room temperature. After $9 \mathrm{~h}$ at the same temperature, the mixture was poured into water and extracted with EtOAc $(100 \mathrm{~mL} \times 3)$. The combined organic layers were washed with brine, dried over anhydrous $\mathrm{Na}_{2} \mathrm{SO}_{4}$, and concentrated at reduced pressure. The resulting residue was purified by column chromatography on silica gel $\left(\mathrm{CH}_{2} \mathrm{Cl}_{2}\right.$ : $\mathrm{MeOH}, 15: 1)$ to give thiol 5a $(680 \mathrm{mg}, 88 \%)$ as a white solid. ${ }^{1} \mathrm{H}$ NMR $\left(\mathrm{CD}_{3} \mathrm{OD}, 300\right.$ MHz) $\delta 6.55($ br s, 1H), $5.38(\mathrm{~s}, 1 \mathrm{H}), \quad 5.14(\mathrm{~s}, 1 \mathrm{H}), 4.93(\mathrm{~s}, 1 \mathrm{H}), 4.25-3.00(\mathrm{~m}, 22 \mathrm{H})$, $2.75(\mathrm{t}, J=7.0 \mathrm{~Hz}, 2 \mathrm{H}), 2.63(\mathrm{t}, J=6.9 \mathrm{~Hz}, 2 \mathrm{H}), 2.00-1.75(\mathrm{~m}, 3 \mathrm{H}), 1.55-1.20(\mathrm{~m}$, 55H); HRMS (FAB) calcd for $\mathrm{C}_{56} \mathrm{H}_{100} \mathrm{~N}_{6} \mathrm{O}_{24} \mathrm{~S}_{2} \mathrm{Na}\left(\mathrm{M}+\mathrm{Na}^{+}\right)$1327.6128, found 1327.6118.

Compound $7 \boldsymbol{a}$ To a mixture of thiol $5 \mathbf{a}(450 \mathrm{mg}, 0.34 \mathrm{mmol}), \mathrm{Bu}_{4} \mathrm{~N}^{+} \mathrm{I}^{-}(64 \mathrm{mg}, 0.17$ mmol) and $\mathrm{Cs}_{2} \mathrm{CO}_{3}(168 \mathrm{mg}, 0.52 \mathrm{mmol})$ in $\mathrm{DMF}(3.4 \mathrm{~mL})$ was added a solution of amide $6(300 \mathrm{mg}, 0.53 \mathrm{mmol})$ in DMF $(1.5 \mathrm{~mL})$ at room temperature. After $72 \mathrm{~h}$ at the same temperature, the mixture was poured into water and extracted with EtOAc $(70 \mathrm{~mL}$ 
$\times 3$ ). The combined organic layers were washed with brine, dried over anhydrous $\mathrm{Na}_{2} \mathrm{SO}_{4}$, and concentrated at reduced pressure. The residue was purified by column chromatography on silica gel $\left(\mathrm{CH}_{2} \mathrm{Cl}_{2}: \mathrm{MeOH}, 15: 1\right)$ to furnish sulfide 7a (199 $\mathrm{mg}$, $32 \%)$ as a white solid. ${ }^{1} \mathrm{H}$ NMR $\left(\mathrm{CDCl}_{3}, 300 \mathrm{MHz}\right) \delta 8.18(\mathrm{~d}, J=8.6 \mathrm{~Hz}, 2 \mathrm{H}), 7.47(\mathrm{~d}, J$ $=8.6 \mathrm{~Hz}, 2 \mathrm{H}), 7.32(\mathrm{t}, J=8.3 \mathrm{~Hz}, 1 \mathrm{H}), 6.20-5.85(\mathrm{~m}, 2 \mathrm{H}), 5.60-5.30(\mathrm{~m}, 2 \mathrm{H}), 5.24(\mathrm{~s}$, 1H), 5.20-5.05 (m, 3H), $4.96(\mathrm{~s}, 1 \mathrm{H}), 4.30-3.05$ (m, 29H), 2.90-2.30 (m, 9H), 2.00-1.75 (m, 4H), 1.50-1.30 (m, 54H), $0.85(\mathrm{~s}, 9 \mathrm{H}), 0.82(\mathrm{~s}, 9 \mathrm{H}), 0.01(\mathrm{~s}, 3 \mathrm{H}), 0.00(\mathrm{~s}, 3 \mathrm{H}),-0.02$ $(\mathrm{s}, 3 \mathrm{H}),-0.23(\mathrm{~s}, 3 \mathrm{H})$; HRMS (FAB) calcd for $\mathrm{C}_{79} \mathrm{H}_{140} \mathrm{~N}_{8} \mathrm{O}_{29} \mathrm{~S}_{2} \mathrm{Si}_{2} \mathrm{Na}\left(\mathrm{M}+\mathrm{Na}^{+}\right)$ 1807.8604, found 1807.8638.

Compound $8 \boldsymbol{a}$ To a solution of silyl ether 7a (74 mg, $0.041 \mathrm{mmol})$ in THF (0.8 mL) was added TBAF $(0.12 \mathrm{~mL}, 1.0 \mathrm{M}$ solution in THF) at room temperature. After $2 \mathrm{~h}$ at the same temperature, the mixture was concentrated and dissolved in EtOAc. The solution was washed with $0.5 \mathrm{~N}$ aqueous $\mathrm{HCl}$ and brine, dried over anhydrous $\mathrm{Na}_{2} \mathrm{SO}_{4}$, and concentrated at reduced pressure. The residue was purified by column chromatography on silica gel $\left(\mathrm{CH}_{2} \mathrm{Cl}_{2}: \mathrm{MeOH}, 15: 1\right)$ to furnish carbamate $\mathbf{8 a}(52 \mathrm{mg}, 81 \%)$ as a white solid. ${ }^{1} \mathrm{H}$ NMR $\left(\mathrm{CDCl}_{3}, 300 \mathrm{MHz}\right) \delta 8.17(\mathrm{~d}, J=7.0 \mathrm{~Hz}, 2 \mathrm{H}), 7.60-7.40(\mathrm{~m}, 3 \mathrm{H}), 6.30-$ $4.80(\mathrm{~m}, 9 \mathrm{H}), 4.30-3.00(\mathrm{~m}, 31 \mathrm{H}), 2.90-2.20(\mathrm{~m}, 9 \mathrm{H}), 1.90-1.20(\mathrm{~m}, 58 \mathrm{H})$; HRMS 
(FAB) calcd for $\mathrm{C}_{67} \mathrm{H}_{112} \mathrm{~N}_{8} \mathrm{O}_{29} \mathrm{~S}_{2} \mathrm{Na}\left(\mathrm{M}+\mathrm{Na}^{+}\right)$1579.6874, found 1579.6881 .

NC1 (3a) A mixture of carbamate $8 \mathbf{a}(52 \mathrm{mg}, 0.033 \mathrm{mmol})$ and TFA (1.0 mL) was stirred for $40 \mathrm{~min}$ at room temperature. The mixture was concentrated at reduced pressure and the resulting residue was filtered through a short silica gel column $\left(\mathrm{CH}_{2} \mathrm{Cl}_{2}: \mathrm{MeOH}, 4: 1\right)$. The filtrate was concentrated at reduced pressure and the residue was purified by prep-HPLC (RP-C18 column, $\mathrm{H}_{2} \mathrm{O}$ containing $0.1 \%$ TFA : MeCN containing $0.1 \%$ TFA, 70:30) to give 3a.6TFA salt $(41 \mathrm{mg}, 75 \%)$ as a white solid. ${ }^{1} \mathrm{H}$ NMR ( $\left.\mathrm{D}_{2} \mathrm{O}, 300 \mathrm{MHz}\right) \delta 8.06(\mathrm{~d}, J=8.7 \mathrm{~Hz}, 2 \mathrm{H}), 7.47(\mathrm{~d}, J=8.7 \mathrm{~Hz}, 2 \mathrm{H}), 5.87(\mathrm{~d}, J=$ $3.7 \mathrm{~Hz}, 1 \mathrm{H}), 5.21(\mathrm{~d}, J=2.1 \mathrm{~Hz}, 1 \mathrm{H}), 5.13(\mathrm{~s}, 1 \mathrm{H}), 5.02(\mathrm{~d}, J=2.3 \mathrm{~Hz}, 1 \mathrm{H}), 4.24-4.04$ $(\mathrm{m}, 6 \mathrm{H}), 3.95-2.80(\mathrm{~m}, 22 \mathrm{H}), 2.68-2.44(\mathrm{~m}, 2 \mathrm{H}), 2.37-2.23(\mathrm{~m}, 3 \mathrm{H}), 2.14-1.90(\mathrm{~m}, 2 \mathrm{H})$, $1.82-1.43(\mathrm{~m}, 3 \mathrm{H}), 1.13-1.03(\mathrm{~m}, 1 \mathrm{H}) ;{ }^{13} \mathrm{C} \mathrm{NMR}\left(\mathrm{D}_{2} \mathrm{O}, 75 \mathrm{MHz}\right) \delta 172.8,163.4(\mathrm{q}, J=$ $35 \mathrm{~Hz}), 150.1,147.3,127.4,124.0,116.8$ (q, $J=290 \mathrm{~Hz}), 110.8,96.1,95.4,86.0,80.6$, $79.1,76.2,74.2,73.0,71.2,71.1,70.5,69.8,68.5,68.0,67.8,61.8,56.9,54.1,51.3$, 50.2, 48.9, 40.9, 40.7, 35.2, 34.6, 30.8, 30.7, 28.3; HRMS (MALDI) calcd for $\mathrm{C}_{37} \mathrm{H}_{64} \mathrm{~N}_{8} \mathrm{O}_{17} \mathrm{~S}_{2} \mathrm{Na}\left(\mathrm{M}+\mathrm{Na}^{+}\right)$979.3829, found 979.1777.

Compound $5 \boldsymbol{b}$ To a solution of sulfonate 4 (1.00 g, $0.67 \mathrm{mmol})$ in DMF (13.4 mL) were 
added 1,6-hexanedithiol $(0.82 \mathrm{~mL}, 5.36 \mathrm{mmol})$ and $\mathrm{Cs}_{2} \mathrm{CO}_{3}(414 \mathrm{mg}, 1.27 \mathrm{mmol})$ at room temperature. After $9 \mathrm{~h}$ at the same temperature, the mixture was poured into water and extracted with EtOAc $(100 \mathrm{~mL} \times 3)$. The combined organic layers were washed with brine, dried over anhydrous $\mathrm{Na}_{2} \mathrm{SO}_{4}$, and concentrated at reduced pressure. The resulting residue was purified by column chromatography on silica gel $\left(\mathrm{CH}_{2} \mathrm{Cl}_{2}: \mathrm{MeOH}\right.$, 15:1) to give thiol $\mathbf{5 b}(773 \mathrm{mg}, 85 \%)$ as a white solid. ${ }^{1} \mathrm{H} \mathrm{NMR}\left(\mathrm{CDCl}_{3}, 300 \mathrm{MHz}\right) \delta$ 6.20-4.96(m, 9H), 4.13-2.80 (m, 27H), 2.72-2.60 (m, 2H), 2.50-2.40 (m, 4H), 1.66-1.30 (m, 64H); HRMS (FAB) calcd for $\mathrm{C}_{59} \mathrm{H}_{106} \mathrm{~N}_{6} \mathrm{O}_{24} \mathrm{~S}_{2} \mathrm{Na}\left(\mathrm{M}+\mathrm{Na}^{+}\right)$1369.6598, found 1369.6565 .

Compound $7 \boldsymbol{b}$ To a mixture of thiol $5 \mathbf{b}(326 \mathrm{mg}, 0.24 \mathrm{mmol})$ and $\mathrm{Cs}_{2} \mathrm{CO}_{3}(98 \mathrm{mg}, 0.30$ mmol) in DMF (3.0 mL) was added a solution of amide $6(170 \mathrm{mg}, 0.30 \mathrm{mmol})$ in DMF $(1.0 \mathrm{~mL})$ at room temperature. After $8 \mathrm{~h}$ at the same temperature, the mixture was poured into water and extracted with EtOAc $(70 \mathrm{~mL} \times 3)$. The combined organic layers were washed with brine, dried over anhydrous $\mathrm{Na}_{2} \mathrm{SO}_{4}$, and concentrated at reduced pressure. The residue was purified by column chromatography on silica gel $\left(\mathrm{CH}_{2} \mathrm{Cl}_{2}\right.$ : $\mathrm{MeOH}, 15: 1)$ to furnish sulfide $7 \mathbf{b}(383 \mathrm{mg}, 87 \%)$ as a white solid. ${ }^{1} \mathrm{H} \mathrm{NMR}\left(\mathrm{CDCl}_{3}\right.$, $300 \mathrm{MHz}) \delta 8.16(\mathrm{~d}, J=8.7 \mathrm{~Hz}, 2 \mathrm{H}), 7.46(\mathrm{~d}, J=8.6 \mathrm{~Hz}, 2 \mathrm{H}), 7.39(\mathrm{~d}, J=8.6 \mathrm{~Hz}, 1 \mathrm{H})$, 
6.15-5.90 (m, 2H), 5.60-5.30 (m, 2H) $5.25(\mathrm{~s}, 1 \mathrm{H}), 5.13-5.11(\mathrm{~m}, 3 \mathrm{H}), 4.95(\mathrm{~s}, 1 \mathrm{H})$, 4.15-3.00 (m, 30H), 2.79-2.18 (m, 8H), 1.79-1.33 (m, 64H), $0.96(\mathrm{~s}, 9 \mathrm{H}), 0.93(\mathrm{~s}, 9 \mathrm{H})$, $0.12(\mathrm{~s}, 3 \mathrm{H}), 0.11(\mathrm{~s}, 3 \mathrm{H}), 0.08(\mathrm{~s}, 3 \mathrm{H}),-0.13(\mathrm{~s}, 3 \mathrm{H})$; HRMS (FAB) calcd for $\mathrm{C}_{82} \mathrm{H}_{146} \mathrm{~N}_{8} \mathrm{O}_{29} \mathrm{~S}_{2} \mathrm{Si}_{2} \mathrm{Na}\left(\mathrm{M}+\mathrm{Na}^{+}\right)$1849.9073, found 1849.9092.

Compound $8 \boldsymbol{b}$ To a solution of silyl ether $7 \mathbf{b}$ (245 $\mathrm{mg}, 0.13 \mathrm{mmol})$ in THF (2.6 mL) was added TBAF (0.40 mL, 1.0 M solution in THF) at room temperature. After $2 \mathrm{~h}$ at the same temperature, the mixture was concentrated and dissolved in EtOAc. The solution was washed with $0.5 \mathrm{~N}$ aqueous $\mathrm{HCl}$ and brine, dried over anhydrous $\mathrm{Na}_{2} \mathrm{SO}_{4}$, and concentrated at reduced pressure. The residue was purified by column chromatography on silica gel $\left(\mathrm{CH}_{2} \mathrm{Cl}_{2}: \mathrm{MeOH}, 15: 1\right)$ to furnish carbamate $\mathbf{8 b}(184 \mathrm{mg}, 86 \%)$ as a white solid. ${ }^{1} \mathrm{H} \mathrm{NMR}\left(\mathrm{CDCl}_{3}, 300 \mathrm{MHz}\right) \delta 8.23(\mathrm{~d}, J=8.6 \mathrm{~Hz}, 2 \mathrm{H}), 7.68(\mathrm{~d}, J=8.5 \mathrm{~Hz}, 2 \mathrm{H})$, $7.56(\mathrm{~d}, J=8.6 \mathrm{~Hz}, 1 \mathrm{H}), 6.19(\mathrm{br} \mathrm{s}, 2 \mathrm{H}), 5.75-5.01(\mathrm{~m}, 7 \mathrm{H}), 4.25-3.00(\mathrm{~m}, 32 \mathrm{H}), 2.90-$ $2.38(\mathrm{~m}, 8 \mathrm{H}), 1.72-1.30(\mathrm{~m}, 64 \mathrm{H})$.

NC2 (3b) A mixture of carbamate $8 \mathbf{b}(184 \mathrm{mg}, 0.12 \mathrm{mmol})$ and TFA (3.0 mL) was stirred for $1 \mathrm{~h}$ at room temperature. The mixture was concentrated at reduced pressure and the resulting residue was filtered through a short silica gel column $\left(\mathrm{CH}_{2} \mathrm{Cl}_{2}: \mathrm{MeOH}\right.$, 
4:1). The filtrate was concentrated at reduced pressure and the residue was purified by prep-HPLC (RP-C18 column, $\mathrm{H}_{2} \mathrm{O}$ containing $0.1 \%$ TFA : MeCN containing $0.1 \%$ TFA, 70:30) to give $3 \mathbf{b} \cdot 6 \mathrm{TFA}$ salt $(117 \mathrm{mg}, 60 \%)$ as a white solid. ${ }^{1} \mathrm{H}$ NMR $\left(\mathrm{D}_{2} \mathrm{O}, 300 \mathrm{MHz}\right)$ $\delta 8.17(\mathrm{~d}, J=8.7 \mathrm{~Hz}, 2 \mathrm{H}), 7.58(\mathrm{~d}, J=8.7 \mathrm{~Hz}, 2 \mathrm{H}), 6.05(\mathrm{~d}, J=3.9 \mathrm{~Hz}, 1 \mathrm{H}), 5.35(\mathrm{~s}$, 1H), $5.24(\mathrm{~s}, 1 \mathrm{H}), 5.14(\mathrm{~d}, J=2.0 \mathrm{~Hz}, 1 \mathrm{H}), 4.39(\mathrm{~s}, 2 \mathrm{H}), 4.30-4.16(\mathrm{~m}, 4 \mathrm{H}), 4.08-3.22$ (m, 19H), 3.17-3.11 (m, 2H), 3.04-2.99 (m, 2H), 2.82-2.75 (m, 1H), $2.54(\mathrm{t}, J=7.2 \mathrm{~Hz}$, 2H), 2.43-2.39 (m, 1H), 2.16-2.07 (m, 1H), 1.97-1.83 (m, 2H), 1.50-1.45 (m, 2H), 1.32$1.11(\mathrm{~m}, 8 \mathrm{H}) ;{ }^{13} \mathrm{C}$ NMR $\left(\mathrm{D}_{2} \mathrm{O}, 75 \mathrm{MHz}\right) \delta 173.1,163.3(\mathrm{q}, J=35 \mathrm{~Hz}), 150.0,147.3$, 127.4, 124.0, $116.9(\mathrm{q}, J=291 \mathrm{~Hz}), 110.9,96.0,95.3,85.9,80.6,79.0,75.4,74.1,72.9$, 71.6, 71.0, 70.6, 69.9, 68.4, 68.0, 67.7, 61.8, 56.8, 54.1, 51.3, 50.2, 49.3, 48.9, 40.9, $35.3, \quad 34.7, \quad 32.1, \quad 32.0, \quad 30.4, \quad 29.2, \quad 28.4, \quad 27.9$; HRMS (MALDI) calcd for $\mathrm{C}_{40} \mathrm{H}_{70} \mathrm{~N}_{8} \mathrm{O}_{17} \mathrm{~S}_{2} \mathrm{Na}\left(\mathrm{M}+\mathrm{Na}^{+}\right)$1021.4198, found 1021.2352.

Compound $5 \boldsymbol{c}$ To a solution of sulfonate $4(1.00 \mathrm{~g}, 0.67 \mathrm{mmol})$ in DMF (13.4 mL) were added 1,9-nonanedithiol $(1.1 \mathrm{~mL}, 5.44 \mathrm{mmol})$ and $\mathrm{Cs}_{2} \mathrm{CO}_{3}(414 \mathrm{mg}, 1.27 \mathrm{mmol})$ at room temperature. After $9 \mathrm{~h}$ at the same temperature, the mixture was poured into water and extracted with EtOAc $(100 \mathrm{~mL} \times 3)$. The combined organic layers were washed with brine, dried over anhydrous $\mathrm{Na}_{2} \mathrm{SO}_{4}$, and concentrated at reduced pressure. The 
resulting residue was purified by column chromatography on silica gel $\left(\mathrm{CH}_{2} \mathrm{Cl}_{2}: \mathrm{MeOH}\right.$, 15:1) to give thiol $\mathbf{5 c}(706 \mathrm{mg}, 76 \%)$ as a white solid. ${ }^{1} \mathrm{H} \mathrm{NMR}\left(\mathrm{CDCl}_{3}, 300 \mathrm{MHz}\right) \delta$ 6.02-4.84 (m, 9H), 4.20-2.90 (m, 27H), 2.70-2.10 (m, 6H), 1.60-1.10 (m, 70H); HRMS (FAB) calcd for $\mathrm{C}_{62} \mathrm{H}_{112} \mathrm{~N}_{6} \mathrm{O}_{24} \mathrm{~S}_{2} \mathrm{Na}\left(\mathrm{M}+\mathrm{Na}^{+}\right)$1411.7067, found 1411.7056.

Compound $7 \boldsymbol{c}$ To a mixture of thiol $5 \mathbf{c}(255 \mathrm{mg}, 0.18 \mathrm{mmol})$ and $\mathrm{Cs}_{2} \mathrm{CO}_{3}(78 \mathrm{mg}, 0.24$ mmol) in DMF (2.0 mL) was added a solution of amide 6 (135 mg, $0.24 \mathrm{mmol})$ in DMF $(1.0 \mathrm{~mL})$ at room temperature. After $8 \mathrm{~h}$ at the same temperature, the mixture was poured into water and extracted with EtOAc $(70 \mathrm{~mL} \times 3)$. The combined organic layers were washed with brine, dried over anhydrous $\mathrm{Na}_{2} \mathrm{SO}_{4}$, and concentrated at reduced pressure. The residue was purified by column chromatography on silica gel $\left(\mathrm{CH}_{2} \mathrm{Cl}_{2}\right.$ : $\mathrm{MeOH}, 15: 1)$ to furnish sulfide $7 \mathrm{c}(254 \mathrm{mg}, 74 \%)$ as a white solid. ${ }^{1} \mathrm{H}$ NMR $\left(\mathrm{CDCl}_{3}\right.$, $300 \mathrm{MHz}) \delta 8.17(\mathrm{~d}, J=8.5 \mathrm{~Hz}, 2 \mathrm{H}), 7.48-7.43(\mathrm{~m}, 3 \mathrm{H}), 6.30-4.95(\mathrm{~m}, 9 \mathrm{H}), 4.20-3.10$ (m, 29H), 3.00-2.25 (m, 9H), 1.50-1.23 (m, 70H), $0.97(\mathrm{~s}, 9 \mathrm{H}), 0.94(\mathrm{~s}, 9 \mathrm{H}), 0.13(\mathrm{~s}$ 3H), $0.12(\mathrm{~s}, \quad 3 \mathrm{H}), 0.09 \quad(\mathrm{~s}, \quad 3 \mathrm{H}), \quad-0.13 \quad(\mathrm{~s}, \quad 3 \mathrm{H})$; HRMS (FAB) calcd for $\mathrm{C}_{85} \mathrm{H}_{152} \mathrm{~N}_{8} \mathrm{O}_{29} \mathrm{~S}_{2} \mathrm{Si}_{2} \mathrm{Na}\left(\mathrm{M}+\mathrm{Na}^{+}\right)$1891.9543, found 1891.9576.

Compound $8 \boldsymbol{c}$ To a solution of silyl ether $7 \mathrm{c}(157 \mathrm{mg}, 0.13 \mathrm{mmol})$ in THF $(1.7 \mathrm{~mL})$ was 
added TBAF $(0.25 \mathrm{~mL}, 1.0 \mathrm{M}$ solution in THF) at room temperature. After $2 \mathrm{~h}$ at the same temperature, the mixture was concentrated and dissolved in EtOAc. The solution was washed with $0.5 \mathrm{~N}$ aqueous $\mathrm{HCl}$ and brine, dried over anhydrous $\mathrm{Na}_{2} \mathrm{SO}_{4}$, and concentrated at reduced pressure. The residue was purified by column chromatography on silica gel $\left(\mathrm{CH}_{2} \mathrm{Cl}_{2}: \mathrm{MeOH}, 15: 1\right)$ to furnish carbamate $\mathbf{8 c}(114 \mathrm{mg}, 83 \%)$ as a white solid. ${ }^{1} \mathrm{H} \mathrm{NMR}\left(\mathrm{CDCl}_{3}, 300 \mathrm{MHz}\right) \delta 8.17(\mathrm{~d}, J=8.7 \mathrm{~Hz}, 2 \mathrm{H}), 7.62(\mathrm{~d}, J=8.6 \mathrm{~Hz}, 2 \mathrm{H})$, $7.52(\mathrm{~d}, J=8.4 \mathrm{~Hz}, 1 \mathrm{H}), 6.20-4.94(\mathrm{~m}, 10 \mathrm{H}), 4.20-3.00(\mathrm{~m}, 31 \mathrm{H}), 2.90-2.05(\mathrm{~m}, 8 \mathrm{H})$, 1.60-1.24 (m, 70H); HRMS (MALDI) calcd for $\mathrm{C}_{73} \mathrm{H}_{124} \mathrm{~N}_{8} \mathrm{O}_{29} \mathrm{~S}_{2} \mathrm{Na}\left(\mathrm{M}+\mathrm{Na}^{+}\right)$1663.7813, found 1663.7738 .

NC3 (3c) A mixture of carbamate 8c $(114 \mathrm{mg}, 0.069 \mathrm{mmol})$ and TFA (1.0 mL) was stirred for $40 \mathrm{~min}$ at room temperature. The mixture was concentrated at reduced pressure and the resulting residue was filtered through a short silica gel column $\left(\mathrm{CH}_{2} \mathrm{Cl}_{2}: \mathrm{MeOH}, 4: 1\right)$. The filtrate was concentrated at reduced pressure and the residue was purified by prep-HPLC (RP-C18 column, $\mathrm{H}_{2} \mathrm{O}$ containing $0.1 \%$ TFA : MeCN containing $0.1 \%$ TFA, 70:30) to give 3c.6TFA salt $(74 \mathrm{mg}, 62 \%)$ as a white solid. ${ }^{1} \mathrm{H}$ $\operatorname{NMR}\left(\mathrm{D}_{2} \mathrm{O}, 300 \mathrm{MHz}\right) \delta 8.17(\mathrm{~d}, J=8.7 \mathrm{~Hz}, 2 \mathrm{H}), 7.58(\mathrm{~d}, J=8.7 \mathrm{~Hz}, 2 \mathrm{H}), 6.01(\mathrm{~d}, J=$ $3.8 \mathrm{~Hz}, 1 \mathrm{H}), 5.34(\mathrm{~s}, 1 \mathrm{H}), 5.24(\mathrm{~s}, 1 \mathrm{H}), 5.14(\mathrm{~d}, J=2.4 \mathrm{~Hz}, 1 \mathrm{H}), 4.36-4.37(\mathrm{~m}, 7 \mathrm{H})$, 
4.03-3.76 (m, 7H), 3.67-3.00 (m, 12H), 2.82-2.75 (m, 1H), $2.59(\mathrm{t}, J=7.2 \mathrm{~Hz}, 2 \mathrm{H})$, 2.44-2.24 (m, 1H), 2.18-1.83 (m, 4H), 2.56-1.49 (m, 2H), 1.29-1.09 (m, 14H); ${ }^{13} \mathrm{C}$ NMR $\left(\mathrm{D}_{2} \mathrm{O}, 75 \mathrm{MHz}\right) \delta 173.1,163.4(\mathrm{q}, J=35 \mathrm{~Hz}), 149.9,147.3,127.4,124.0,116.8(\mathrm{q}, J=$ $290 \mathrm{~Hz}), 111.0,96.0,95.5,85.9,80.6,79.0,75.5,74.1,72.9,71.5,71.0,70.5,70.0,68.4$, $68.0,67.8,61.7,56.8,54.1,51.3,50.1,48.8,41.0,40.9,35.3,32.2,32.1,29.3,28.8$, 28.6, 28.5, 28.4, 28.3, 28.2; HRMS (MALDI) calcd for $\mathrm{C}_{43} \mathrm{H}_{76} \mathrm{~N}_{8} \mathrm{O}_{17} \mathrm{~S}_{2} \mathrm{Na}\left(\mathrm{M}+\mathrm{Na}^{+}\right)$ 1063.4668, found 1063.2546.

Compound 10 A mixture of dihydroxy amine 9 (3.00 g, 14.14 mmol), Fmoc-Osu (4.77g, $14.14 \mathrm{mmol})$ and $1 \mathrm{~N}$ aqueous $\mathrm{NaHCO}_{3}(28 \mathrm{~mL})$ in ether $(140 \mathrm{~mL})$ was stirred for $24 \mathrm{~h}$. The reaction mixture was poured into $1.0 \mathrm{~N}$ aqueous $\mathrm{HCl}$ and the white precipitate was filtered off. After the filtrate was partitioned, the organic layer was separated, washed with dilute aqueous $\mathrm{HCl}$ and brine, and dried over anhydrous $\mathrm{MgSO}_{4}$. Concentration of the solution at reduced pressure and recrystalization of the crude product at EtOAc/hexane produced carbamate $10(5.83 \mathrm{~g}, 95 \%)$ as a white crystal. ${ }^{1} \mathrm{H}$ NMR $\left(\mathrm{CD}_{3} \mathrm{OD}, 300 \mathrm{MHz}\right) \delta 8.13(\mathrm{~d}, J=8.7 \mathrm{~Hz}, 2 \mathrm{H}), 7.79(\mathrm{~d}, J=7.4 \mathrm{~Hz}, 2 \mathrm{H}), 7.62-7.55(\mathrm{~m}$, 4H), $7.39(\mathrm{t}, J=7.3 \mathrm{~Hz}, 2 \mathrm{H}), 7.32-7.26(\mathrm{~m}, 2 \mathrm{H}), 5.08(\mathrm{~s}, 1 \mathrm{H}), 4.30-4.08$ (m, 3H), 3.91$3.86(\mathrm{~m}, 1 \mathrm{H}), 3.80-3.74(\mathrm{~m}, 1 \mathrm{H}), 3.59-3.49(\mathrm{~m}, 1 \mathrm{H})$; HRMS (FAB) calcd for 
$\mathrm{C}_{24} \mathrm{H}_{23} \mathrm{~N}_{2} \mathrm{O}_{6}\left(\mathrm{MH}^{+}\right)$435.1556, found 435.1552.

Compound 11 To a suspension of carbamate $10(2.90 \mathrm{~g}, 6.68 \mathrm{mmol})$ in $\mathrm{CH}_{2} \mathrm{Cl}_{2}(67 \mathrm{~mL})$ were added 2,6-lutidine (3.1 mL, $26.72 \mathrm{mmol})$ and TBSOTf $(4.6 \mathrm{~mL}, 20.04 \mathrm{mmol})$ at 0 ${ }^{\circ} \mathrm{C}$. After $4 \mathrm{~h}$ at the same temperature, the mixture was diluted with $\mathrm{CH}_{2} \mathrm{Cl}_{2}$, washed with dilute aqueous $\mathrm{HCl}$ and brine. The organic layer was dried over anhydrous $\mathrm{Na}_{2} \mathrm{SO}_{4}$ and concentrated at reduced pressure. The resulting residue was purified by column chromatography on silica gel (EtOAc : hexane, 1:10) to give silyl ether 11 (4.30 g, 97\%) as a thick syrup. ${ }^{1} \mathrm{H} \mathrm{NMR}\left(\mathrm{CDCl}_{3}, 300 \mathrm{MHz}\right) \delta 8.18(\mathrm{~d}, J=8.6 \mathrm{~Hz}, 2 \mathrm{H}), 7.79(\mathrm{~d}, J=7.5$ $\mathrm{Hz}, 2 \mathrm{H}), 7.57-7.28(\mathrm{~m}, 8 \mathrm{H}), 5.20(\mathrm{~d}, J=2.0 \mathrm{~Hz}, 1 \mathrm{H}), 5.11(\mathrm{~d}, J=9.0 \mathrm{~Hz}, 1 \mathrm{H}), 4.33(\mathrm{~d}, J$ $=7.1 \mathrm{~Hz}, 2 \mathrm{H}), 4.20(\mathrm{~d}, J=6.9 \mathrm{~Hz}, 1 \mathrm{H}), 3.79-3.75(\mathrm{~m}, 1 \mathrm{H}), 3.62(\mathrm{~d}, J=7.1 \mathrm{~Hz}, 2 \mathrm{H})$, 0.98-0.90 (m, 18H), 0.14-0.06 (m, 6H); HRMS (FAB) calcd for $\mathrm{C}_{36} \mathrm{H}_{51} \mathrm{~N}_{2} \mathrm{O}_{6} \mathrm{Si}_{2}\left(\mathrm{MH}^{+}\right)$ 663.3286, found 663.3294.

Compound 12 A mixture of silyl ether $11(3.79 \mathrm{~g}, 5.72 \mathrm{mmol})$ and piperidine (4.0 mL, $45.71 \mathrm{mmol})$ in DMF $(16.0 \mathrm{~mL})$ was stirred for $1 \mathrm{~h}$ at room temperature. The mixture was poured into water and extracted with EtOAc $(150 \mathrm{~mL} \times 3)$. The combined organic layers were washed with brine, dried over anhydrous $\mathrm{Na}_{2} \mathrm{SO}_{4}$ and concentrated at 
reduced pressure. The resulting residue was purified by column chromatography on silica gel (EtOAc : hexane, 1:10) to furnish amine $12(2.47 \mathrm{~g}, 98 \%)$ as a thick syrup. ${ }^{1} \mathrm{H}$ $\operatorname{NMR}\left(\mathrm{CDCl}_{3}, 300 \mathrm{MHz}\right) \delta 8.21(\mathrm{~d}, J=8.6 \mathrm{~Hz}, 2 \mathrm{H}), 7.49(\mathrm{~d}, J=8.7 \mathrm{~Hz}, 2 \mathrm{H}), 4.90(\mathrm{~d}, J$ $=4.4 \mathrm{~Hz}, 2 \mathrm{H}), 3.55(\mathrm{dd}, J=10.0,6.3 \mathrm{~Hz}, 1 \mathrm{H}), 3.40(\mathrm{dd}, J=10.0,5.1 \mathrm{~Hz}, 1 \mathrm{H}), 2.77-$ $2.71(\mathrm{~m}, 1 \mathrm{H}), 0.94(\mathrm{~s}, 9 \mathrm{H}), 0.93(\mathrm{~s}, 9 \mathrm{H}), 0.09(\mathrm{~s}, 3 \mathrm{H}), 0.07$ (s, 6H), -0.13(s, 3H); HRMS (FAB) calcd for $\mathrm{C}_{21} \mathrm{H}_{41} \mathrm{~N}_{2} \mathrm{O}_{4} \mathrm{Si}_{2}\left(\mathrm{MH}^{+}\right)$441.2605, found 441.2605.

Compound 6 To a solution of amine 12 (1.67 g, $3.79 \mathrm{mmol})$ in $\mathrm{CH}_{2} \mathrm{Cl}_{2}$ were added pyridine $(0.77 \mathrm{~mL}, 9.52 \mathrm{mmol})$ and bromoacetyl bromide $(0.43 \mathrm{~mL}, 4.94 \mathrm{mmol})$ at $0{ }^{\circ} \mathrm{C}$. After $1 \mathrm{~h}$ at the same temperature, the mixture was diluted with EtOAc and washed with brine. The organic layer was dried over anhydrous $\mathrm{Na}_{2} \mathrm{SO}_{4}$ and concentrated at reduced pressure. The resulting residue was purified by column chromatography on silica gel (EtOAc : hexane, $1: 10)$ to give amide $6(2.00 \mathrm{~g}, 94 \%)$ as a thick syrup. ${ }^{1} \mathrm{H} \mathrm{NMR}\left(\mathrm{CDCl}_{3}\right.$, $300 \mathrm{MHz}) \delta 8.18(\mathrm{~d}, J=8.7 \mathrm{~Hz}, 2 \mathrm{H}), 7.47(\mathrm{~d}, J=8.6 \mathrm{~Hz}, 2 \mathrm{H}), 7.07(\mathrm{~d}, J=8.9 \mathrm{~Hz}, 1 \mathrm{H})$, $5.21(\mathrm{~d}, J=2.2 \mathrm{~Hz}, 1 \mathrm{H}), 3.98-3.90(\mathrm{~m}, 1 \mathrm{H}), 3.85(\mathrm{~d}, J=14.2 \mathrm{~Hz}, 1 \mathrm{H}), 3.75(\mathrm{~d}, J=14.2$ $\mathrm{Hz}, 1 \mathrm{H}), 3.63-3.52(\mathrm{~m}, 2 \mathrm{H}), 0.95(\mathrm{~s}, 9 \mathrm{H}), 0.93(\mathrm{~s}, 9 \mathrm{H}), 0.12(\mathrm{~s}, 3 \mathrm{H}), 0.10(\mathrm{~s}, 3 \mathrm{H}), 0.08$ (s, 3H), -0.15 (s, 3H); ${ }^{13} \mathrm{C} \mathrm{NMR}\left(\mathrm{CDCl}_{3}, 75 \mathrm{MHz}\right) \delta 164.6,149.7,147.4,126.8,123.5$, 70.5, 60.6, 57.6, 29.4, 25.8, 25.7, 18.0, -4.6, -5.3, -5.4, -5.5; HRMS (FAB) calcd for 
$\mathrm{C}_{23} \mathrm{H}_{42} \mathrm{BrN}_{2} \mathrm{O}_{5} \mathrm{Si}_{2}\left(\mathrm{MH}^{+}\right)$561.1815, found 561.1816.

Compound 15 To a suspension of oxazolidinone $13(34 \mathrm{mg}, 0.10 \mathrm{mmol})$ in $\mathrm{CH}_{2} \mathrm{Cl}_{2}(2.0$ $\mathrm{mL})$ were added pyridine $(0.025 \mathrm{~mL}, 0.31 \mathrm{mmol})$, and bromoacetyl bromide $(0.013 \mathrm{~mL}$, $0.15 \mathrm{mmol})$ at $0{ }^{\circ} \mathrm{C}$. After $1 \mathrm{~h}$ at the same temperature, the mixture was diluted with EtOAc and washed with brine. The organic layer was dried over anhydrous $\mathrm{Na}_{2} \mathrm{SO}_{4}$, and concentrated at reduced pressure. The resulting residue was purified by column chromatography on silica gel $\left(\mathrm{CH}_{2} \mathrm{Cl}_{2}: \mathrm{MeOH}, 10: 1\right)$ to furnish bromoamide 15 (33 mg, $72 \%)$ as a white solid. ${ }^{1} \mathrm{H} \mathrm{NMR}\left(\mathrm{CDCl}_{3}, 300 \mathrm{MHz}\right) \delta 7.50(\mathrm{dd}, J=14.2,2.5 \mathrm{~Hz}, 1 \mathrm{H})$, $7.10(\mathrm{dd}, J=8.8,2.4 \mathrm{~Hz}, 1 \mathrm{H}), 6.99(\mathrm{t}, J=9.0 \mathrm{~Hz}, 1 \mathrm{H}), 6.13(\mathrm{t}, J=6.1 \mathrm{~Hz}, 1 \mathrm{H}), 4.82-$ $4.76(\mathrm{~m}, 1 \mathrm{H}), 4.13-3.51(\mathrm{~m}, 10 \mathrm{H}), 3.16(\mathrm{t}, J=4.9 \mathrm{~Hz}, 2 \mathrm{H}), 3.08(\mathrm{t}, J=5.0 \mathrm{~Hz}, 2 \mathrm{H}), 2.04$ $(\mathrm{s}, 3 \mathrm{H})) ;{ }^{13} \mathrm{C} \mathrm{NMR}\left(\mathrm{CD}_{3} \mathrm{SOCD}_{3}, 75 \mathrm{MHz}\right) \delta 170.0,164.9,154.7(\mathrm{~d}, J=243 \mathrm{~Hz}), 154.1$, $135.1(\mathrm{~d}, J=9 \mathrm{~Hz}), 133.8(\mathrm{~d}, J=10 \mathrm{~Hz}), 119.9,114.1,106.6(\mathrm{~d}, J=26 \mathrm{~Hz}), 71.6,50.4$, 50.2, 47.3, 46.1, 41.6, 41.4, 27.8, 22.5; HRMS (MALDI) calcd for $\mathrm{C}_{18} \mathrm{H}_{22} \mathrm{BrFN}_{4} \mathrm{O}_{4} \mathrm{Na}$ $\left(\mathrm{M}+\mathrm{Na}^{+}\right)$479.0706, found 479.0675.

Compound 16 A mixture of thiol $5 \mathbf{b}(97 \mathrm{mg}, 0.072 \mathrm{mmol})$, bromoamide 15 (33 mg, $0.072 \mathrm{mmol})$, and $\mathrm{Cs}_{2} \mathrm{CO}_{3}(24 \mathrm{mg}, 0.074 \mathrm{mmol})$ in $\mathrm{DMF}(1.5 \mathrm{~mL})$ was stirred for $15 \mathrm{~h}$ 
at room temperature. The mixture was poured into water and extracted with EtOAc. The organic layer was washed with brine, dried over anhydrous $\mathrm{Na}_{2} \mathrm{SO}_{4}$, and concentrated at reduced pressure. The residue was purified by column chromatography on silica gel $\left(\mathrm{CH}_{2} \mathrm{Cl}_{2}\right.$ : $\left.\mathrm{MeOH}, 10: 1\right)$ to furnish sulfide $16(101 \mathrm{mg}, 81 \%)$ as a white solid. ${ }^{1} \mathrm{H} \mathrm{NMR}$ $\left(\mathrm{CD}_{3} \mathrm{OD}, 300 \mathrm{MHz}\right) \delta 7.53(\mathrm{dd}, J=14.5,2.4 \mathrm{~Hz}, 1 \mathrm{H}), 7.18(\mathrm{dd}, J=8.8 \mathrm{~Hz}, 2.1 \mathrm{~Hz}, 1 \mathrm{H})$, 7.07 (t, $J=9.1 \mathrm{~Hz}, 1 \mathrm{H}), 6.68(\mathrm{br} \mathrm{d}, J=7.7 \mathrm{~Hz}, 1 \mathrm{H}), 6.49$ (br d, $J=6.3 \mathrm{~Hz}, 2 \mathrm{H}), 5.32(\mathrm{br}$ s, 1H), 5.19 (br s, 1H), 4.94 (br s, 1H), 4.83-4.75 (m, 1H), 4.23-2.60 (m, $40 \mathrm{H}), 1.97$ (s, $3 \mathrm{H}), 1.65-1.24(\mathrm{~m}, 64 \mathrm{H})$; HRMS (MALDI) calcd for $\mathrm{C}_{77} \mathrm{H}_{127} \mathrm{FN}_{10} \mathrm{O}_{28} \mathrm{~S}_{2} \mathrm{Na}\left(\mathrm{M}+\mathrm{Na}^{+}\right)$ 1745.8144, found 1745.9488 .

NL (14) A mixture of carbamate $16(101 \mathrm{mg}, 0.059 \mathrm{mmol})$ and TFA (1.5 mL) was stirred for $0.5 \mathrm{~h}$ at room temperature. The mixture was concentrated at reduced pressure. Purification of the residue by prep-HPLC (RP-C18 column, $\mathrm{H}_{2} \mathrm{O}$ containing $0.1 \%$ TFA : MeCN containing 0.1\% TFA, 70:30) and lyophilization furnished 14.7TFA salt $(70 \mathrm{mg}, 62 \%)$ as a white solid. ${ }^{1} \mathrm{H}$ NMR $\left(\mathrm{D}_{2} \mathrm{O}, 300 \mathrm{MHz}\right) \delta 7.09(\mathrm{dd}, J=14.0,1.9 \mathrm{~Hz}$, $1 \mathrm{H}), 6.91-6.87(\mathrm{~m}, 2 \mathrm{H}), 5.70(\mathrm{~d}, J=4.0 \mathrm{~Hz}, 1 \mathrm{H}), 5.04(\mathrm{~d}, J=2.0 \mathrm{~Hz}, 1 \mathrm{H}), 4.94(\mathrm{~d}, J=$ $1.4 \mathrm{~Hz}, 1 \mathrm{H}), 4.04-2.69(\mathrm{~m}, 38 \mathrm{H}), 2.45(\mathrm{dd}, J=13.4,7.6 \mathrm{~Hz}, 1 \mathrm{H}), 2.27(\mathrm{q}, J=7.3 \mathrm{~Hz}$, 4H), 2.17-2.11 (m, 1H), $1.62(\mathrm{~s}, 3 \mathrm{H}), 1.54(\mathrm{q}, J=12.6 \mathrm{~Hz}, 1 \mathrm{H}), 1.29-1.18(\mathrm{~m}, 4 \mathrm{H})$, 
$1.05-1,01(\mathrm{~m}, 4 \mathrm{H}) ;{ }^{13} \mathrm{C}$ NMR $\left(\mathrm{D}_{2} \mathrm{O}, 75 \mathrm{MHz}\right) \delta 175.2,171.2,163.9(\mathrm{q}, J=35 \mathrm{~Hz})$, 157.0, 134.7, 120.9, $116.7(\mathrm{q}, J=290 \mathrm{~Hz}), 116.2,110.8,109.0,108.7,96.0,95.5,85.8$, $80.5,78.9,75.4,74.1,73.2,72.8,71.3,70.4,69.8,68.3,68.0,67.7,54.0,51.4,51.2$, 51.0, 50.0, 48.7, 48.6, 46.2, 42.1, 40.8, 40.7, 34.6, 33.0, 32.1, 31.9, 29.1, 28.7, 28.3, 27.9, 27.7, 22.1. HRMS (MALDI) calcd for $\mathrm{C}_{47} \mathrm{H}_{79} \mathrm{FN}_{10} \mathrm{O}_{16} \mathrm{~S}_{2} \mathrm{Na}\left(\mathrm{M}+\mathrm{Na}^{+}\right)$1145.5001, found 1145.2100. 
6. Table S1. Binding affinities $\left(\mathrm{K}_{\mathrm{d}}\right)$ of conjugates to various RNA targets.

\begin{tabular}{|c|c|c|c|c|c|}
\hline RNA & Neo & NC1 & NC2 & NC3 & NL \\
\hline \multirow{2}{*}{ RRE } & $\begin{array}{c}0.18 \\
(0.043)\end{array}$ & $\begin{array}{c}0.063 \\
(0.011)\end{array}$ & $\begin{array}{c}0.022 \\
(0.0034)\end{array}$ & $\begin{array}{c}0.031 \\
(0.0038)\end{array}$ & $\begin{array}{c}0.54 \\
(0.044)\end{array}$ \\
\hline \multirow{2}{*}{ TAR } & $\begin{array}{c}0.18 \\
(0.018)\end{array}$ & $\begin{array}{c}0.40 \\
(0.088)\end{array}$ & $\begin{array}{c}0.041 \\
(0.0055)\end{array}$ & $\begin{array}{c}0.19 \\
(0.065)\end{array}$ & $\begin{array}{c}0.047 \\
(0.015)\end{array}$ \\
\hline \multirow{2}{*}{ TS } & 0.33 & 0.049 & 0.22 & 2.1 & 0.33 \\
& $(0.077)$ & $(0.0026)$ & $(0.065)$ & $(0.31)$ & $(0.067)$ \\
\hline \multirow{2}{*}{ IRE } & 0.31 & 0.079 & 0.50 & $>4.0$ & 0.12 \\
& $(0.059)$ & $(0.020)$ & $(0.061)$ & $(0.20)$ & $(0.018)$ \\
\hline
\end{tabular}

The values are in $\mu \mathrm{M}$. Error boundary of each value was written in the parenthesis. The binding affinities are measured at $20^{\circ} \mathrm{C}$ by using an LS 50B Luminometer (PerkinElmer). Cam and Lnz binding affinities showed $>10 \mu \mathrm{M}$ to any RNA target. 
7. Table S2. Binding affinities $\left(\mathrm{K}_{\mathrm{d}}\right)$ of conjugates to mutant RNA targets.

\begin{tabular}{|c|c|c|c|}
\hline RRE & Neo & NC2 & NC3 \\
\hline Wild & $\begin{array}{c}0.18 \\
\text { type }\end{array}$ & $\begin{array}{c}0.022 \\
(0.043)\end{array}$ & $\begin{array}{c}0.031 \\
(0.0034)\end{array}$ \\
\hline U13A & $\begin{array}{c}0.18 \\
(0.027)\end{array}$ & $\begin{array}{c}0.22 \\
(0.014)\end{array}$ & $\begin{array}{c}0.14 \\
(0.0033)\end{array}$ \\
\hline G24A & $\begin{array}{c}0.22 \\
(0.039)\end{array}$ & $\begin{array}{c}0.023 \\
(0.0042)\end{array}$ & $\begin{array}{c}0.087 \\
(0.027)\end{array}$ \\
\hline
\end{tabular}

\begin{tabular}{|c|c|c|c|}
\hline TAR & Neo & NC2 & NL \\
\hline Wild & 0.16 & 0.041 & 0.047 \\
\hline type & (0.018) & $(0.0055)$ & $(0.015)$ \\
\hline \multirow{2}{*}{ U10C } & 0.16 & 1.1 & 1.1 \\
\hline & $(0.033)$ & $(0.25)$ & $(0.21)$ \\
\hline \multirow{2}{*}{$\mathrm{C} 15 \mathrm{~A}$} & 0.27 & 0.033 & 0.40 \\
\hline & (0.072) & $(0.0079)$ & $(0.046)$ \\
\hline
\end{tabular}

Conditions are same as in Table S1. Mutation sites are shown in Figure 2. Error boundary of each value was written in the parenthesis. 
7. Experimental procedures for affinity measurement between RNA and compounds using fluorescence anisotropy.

The affinity of the RNA to the cognate molecule was confirmed by a competition assay using a fluorescent anisotropy and CRP (5'-carboxytetramethylrhodamine labeled paromomycin) as a fluorescence probe. A fluorescence anisotropy measurement was performed on a Perkin-Elmer LS-50B luminescence spectrometer equipped with a thermostat at $20^{\circ} \mathrm{C}$. The tracer solution $(10 \mathrm{nM})$ was excited at $550 \mathrm{~nm}$, and monitored at $580 \mathrm{~nm}$. For every single point, five measurements were made and averaged. The measurement was performed in a buffer containing $140 \mathrm{mM} \mathrm{NaCl}, 5 \mathrm{mM} \mathrm{KCl}, 1 \mathrm{mM}$ $\mathrm{MgCl}_{2}$, and $20 \mathrm{mM}$ HEPES at $\mathrm{pH}$ 7.5. The equation in the reference was used for the determination of the dissociation constant between RNA and CRP $\left(\mathrm{K}_{\mathrm{d}}\right)$ :

$\mathrm{A}=\mathrm{A}_{0}+\Delta \mathrm{A}\left\{\left([\mathrm{RNA}]_{0}+[\mathrm{CRP}]_{0}+\mathrm{K}_{\mathrm{d}}\right)-\left([\mathrm{RNA}]_{0}+[\mathrm{CRP}]_{0}+\mathrm{K}_{\mathrm{d}}\right)^{2}-4[\mathrm{RNA}]_{0}[\mathrm{CRP}]_{0}\right.$ $\left.{ }^{1 / 2}\right\} / 2$

Where $\mathrm{A}$ and $\mathrm{A}_{0}$ are the fluorescence anisotropy of CRP in the presence and absence of RNA, respectively, $\Delta \mathrm{A}$ is the different concentration of RNA minus the fluorescence anisotropy in the absence of RNA. $[\mathrm{RNA}]_{0}$ and $[\mathrm{CRP}]_{0}$ are the initial concentrations of RNA and CRP, respectively. 
In the competitive binding assay, the following equation was used for the calculation of $\mathrm{K}_{\mathrm{D}}$ values:

$[\text { Aminoglycoside }]_{0}=\left\{\mathrm{K}_{\mathrm{D}}\left(\mathrm{A}_{\Omega}-\mathrm{A}\right) /\left[\mathrm{K}_{\mathrm{d}}\left(\mathrm{A}-\mathrm{A}_{0}\right)+1\right]\right\}\left\{[\mathrm{RNA}]_{0}-\mathrm{K}_{\mathrm{d}}\left(\mathrm{A}-\mathrm{A}_{0}\right) /\left(\mathrm{A}_{\Omega}-\mathrm{A}_{0}\right)\right.$ $\left.-[\mathrm{CRP}]_{0}\left(\mathrm{~A}-\mathrm{A}_{0}\right) /\left(\mathrm{A}_{\Omega}-\mathrm{A}_{0}\right)\right\}$

Where $K_{D}$ is the dissociation constant between RNA and the aminoglycoside, and $[\text { Aminoglycoside }]_{0}$ is the initial concentration of aminoglycosides. $\mathrm{A}, \mathrm{A}_{\Omega}$, and $\mathrm{A}_{0}$ are fluorescence anisotropy values of the sample, totally bound tracer, and totally free tracer, respectively. Both $K_{d}$ and $K_{D}$ were determined by a nonlinear curve fitting using a KaleidaGraph 3.5 software. 
8. Experimental procedures and data for enzymatic foot printing of RNA

5'-End labeling Briefly, a mixture of $10 \mu \mathrm{g}$ of RNA and 10 units of phosphatase (New England Biolabs) in $200 \mu \mathrm{L}$ of reaction buffer $(100 \mathrm{mM} \mathrm{NaCl}, 50 \mathrm{mM}$ Tris- $\mathrm{HCl}, 10 \mathrm{mM}$ $\mathrm{MgCl}_{2}, 1 \mathrm{mM}$ DTT, $\mathrm{pH}$ 7.9) was incubated for $1 \mathrm{~h}$ at $37^{\circ} \mathrm{C}$. RNA was then purified by ethanol precipitation. Then a mixture of ${ }^{32} \mathrm{P}$-labeled gamma ATP (Amersham Pharmacia Biotech) and the purified RNA was incubated with 50 units of T4 polynucleotide kinase (New England Biolabs) in reaction buffer (70 mM Tris-HCl, $\mathrm{pH} 7.6,10 \mathrm{mM} \mathrm{MgCl}, 5$ mM DTT) for $1 \mathrm{~h}$. The resulting RNA was purified by ethanol precipitation and then gel electrophoresed on $20 \%$ acrylamide-7 M urea. The intended-sized RNA was cut from the gel and was eluted with elution buffer $(0.5 \mathrm{M}$ ammonium acetate, $10 \mathrm{mM}$ magnesium acetate, $0.1 \%$ sodium dodesyl sulfate), followed by ethanol precipitation.

RNA foot-printing Five hundred $\mathrm{nM}$ of $5{ }^{,}-{ }^{32} \mathrm{P}$ end labeled RRE (or TAR) RNA in buffer (20 mM N-(2-hydroxyethyl)piperazine-N'-(2-ethanesulfonic acid; HEPES), $150 \mathrm{mM}$ $\mathrm{NaCl}, 5 \mathrm{mM} \mathrm{KCl}, 1 \mathrm{mM} \mathrm{MgCl} 2,1 \mathrm{mM} \mathrm{CaCl}_{2}$ at $\mathrm{pH}$ 7.4), were heated at $65^{\circ} \mathrm{C}$ for $5 \mathrm{~min}$ and cooled down to room temperature. Various amount of Neo $(1,10,100$ fold concentration of RNA) or conjugates (NC's or NL) was added to the prepared RNA 
solution and incubated for $10 \mathrm{~min}$ at room temperature. To the resulting solution, $1 \mu \mathrm{L}$ of RNAse $(0.1 \mu \mathrm{g} / \mathrm{mL}$ of RNAse A or 0.01 unit $/ \mu \mathrm{L}$ of RNAse V1 for RRE, $0.1 \mu \mathrm{g} / \mathrm{mL}$ of RNAse A or 0.1 unit/ $\mu \mathrm{L}$ of RNase T1 for TAR) was added and incubated for $10 \mathrm{~min}$ at $37^{\circ} \mathrm{C}$. Then the fragmented RNA was obtained by ethanol precipitation and dried out. Resulting RNA was re-dissolved in $5 \mu \mathrm{L}$ of Gel Loading Buffer II (Ambion) and was heated to $65^{\circ} \mathrm{C}$ for $5 \mathrm{~min}$. Half of the resulting solution was loaded on $15 \%$ polyacrylamide/7M urea gel and the gel was run for $3 \mathrm{~h}$ with $1,500 \mathrm{~V}$. The gel was dried over $2 \mathrm{~h}$ at $80^{\circ} \mathrm{C}$ using an aspirator. Radioactivity of the individual bands was monitored by BAS 2000 Phosphorimager (Fujix) and was analyzed by Image Reader Ver. 1.3.E and Image Gauge Ver. 3.3 software (Fuji photo).

Results of RNA foot-printing The autoradiogram of foot-printing RRE and TAR RNA were shown in Figure S4 and S5, respectively. The bar graphs (S6, RRE, Neo, RNAse A; S7, RRE, NC2, RNAse A; S8, RRE, Neo, RNAse V1; S9, RRE, NC2, RNAse V1; S10, TAR, Neo, RNAse A; S11, TAR, NC2, RNAse A; S12, TAR, NL, RNAse A; S13, TAR, Neo, RNAse T1; S14, TAR, NC2, RNAse T1; S15, TAR, NL, RNAse T1) showed quantitative representation of both the suppressed and enhanced cleavages of RNA in the presence of each set of Neo, NC2, or NL. Cleavage pattern was normalized by the 
same method described in the supporting information of reference 9 in the text. 
Figure S4. Autodiagram of the enzymatic cleavage of RRE by RNAse A and RNAse V1. Lane 1, intact RRE; Lane 2, control alkaline hydrolysis; Lane 3 12 contain 0.01 unit RNase V1, RRE 500 nM; Lane 3, RNase V1 control; Lane 4, 500 nM Neomycin; Lane 5, $5 \mu \mathrm{M}$ Neomycin; Lane 6, $50 \mu \mathrm{M}$ Neomycin; Lane 7, $500 \mathrm{nM}$ NC2; Lane 8, $5 \mu \mathrm{M}$ NC2; Lane 9, $50 \mu \mathrm{M}$ NC2; Lane 10, $500 \mathrm{nM}$ NL; Lane 11, $5 \mu \mathrm{M}$ NL; Lane 12, $50 \mu \mathrm{M}$ NL; Lane 13 22 contain $0.1 \mu \mathrm{g} / \mathrm{ml}$ RNase A; Lane 13, RNase A control; Lane 14, 500 nM Neomycin; Lane 15, $5 \mu \mathrm{M}$ Neomycin; Lane 16, $50 \mu \mathrm{M}$ Neomycin; Lane 17, 500 nM NC2; Lane 18, 5 M NC2; Lane 19, $50 \mu \mathrm{M}$ NC2; Lane 20, 500 nM NL; Lane 21, 5 $\mu \mathrm{M}$ NL; Lane 22, $50 \mu \mathrm{M}$ NL

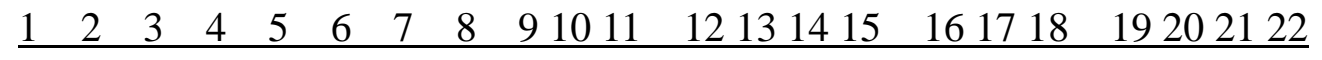

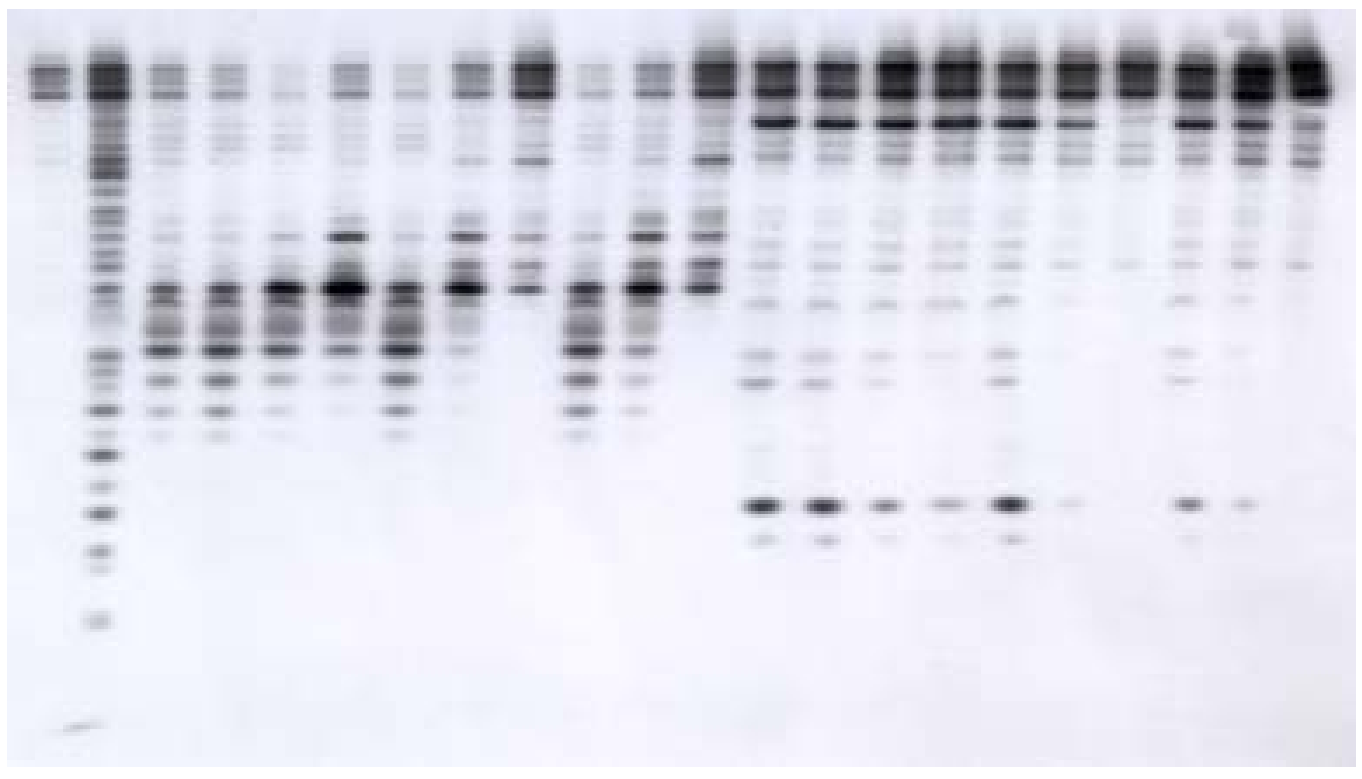


Figure S5. Autodiagram of the enzymatic cleavage of TAR by RNAse A and RNAse T1.

Lane 1, intact TAR; Lane 2, control alkaline hydrolysis; Lane 3 12 contain 0.1 unit RNase T1, TAR 500 nM; Lane 3, RNase T1 control; Lane 4, 500 nM Neomycin; Lane 5, $5 \mu \mathrm{M}$ Neomycin; Lane 6, $50 \mu \mathrm{M}$ Neomycin; Lane 7, 500 nM NC2; Lane 8, $5 \mu \mathrm{M}$ NC2; Lane 9, $50 \mu \mathrm{M}$ NC2; Lane 10, 500 nM NL; Lane 11, $5 \mu \mathrm{M}$ NL; Lane 12, $50 \mu \mathrm{M}$ NL; Lane 13 22 contain $0.1 \mu \mathrm{g} / \mathrm{ml}$ RNase A; Lane 13, RNase A control; Lane 14, $500 \mathrm{nM}$ Neomycin; Lane 15, $5 \mu \mathrm{M}$ Neomycin; Lane 16, $50 \mu \mathrm{M}$ Neomycin; Lane 17, $500 \mathrm{nM}$

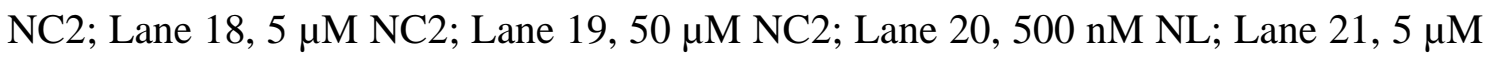
NL; Lane 22, $50 \mu \mathrm{M}$ NL

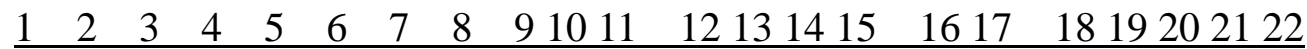

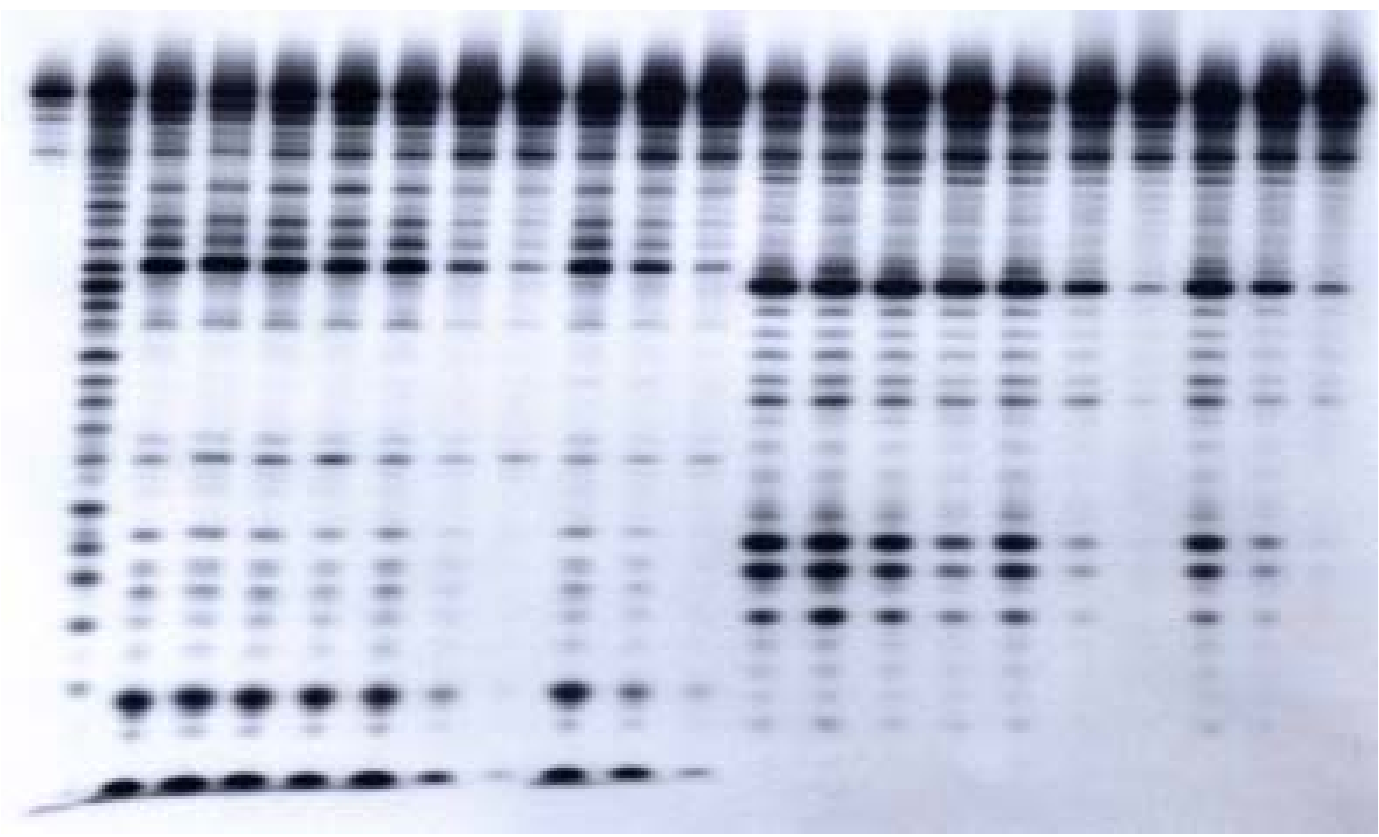


Figure S6

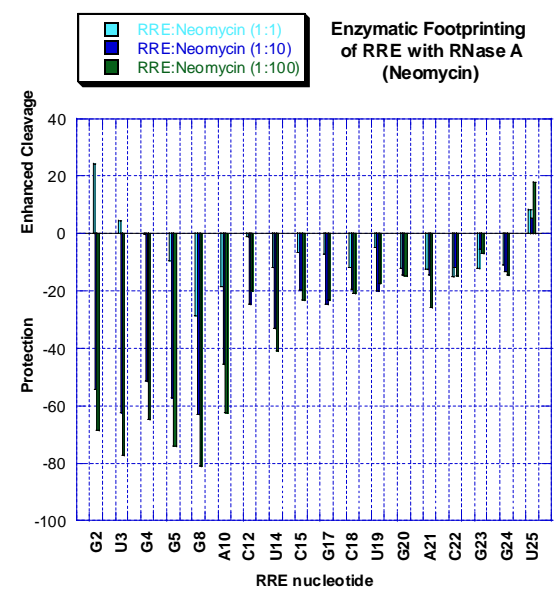

Figure S8

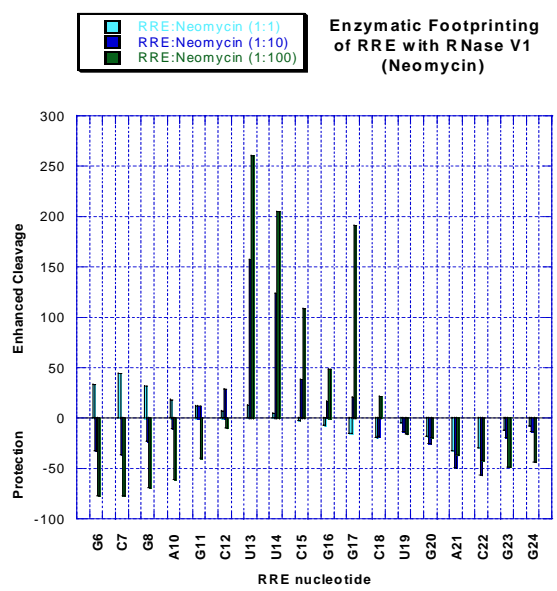

Figure S10

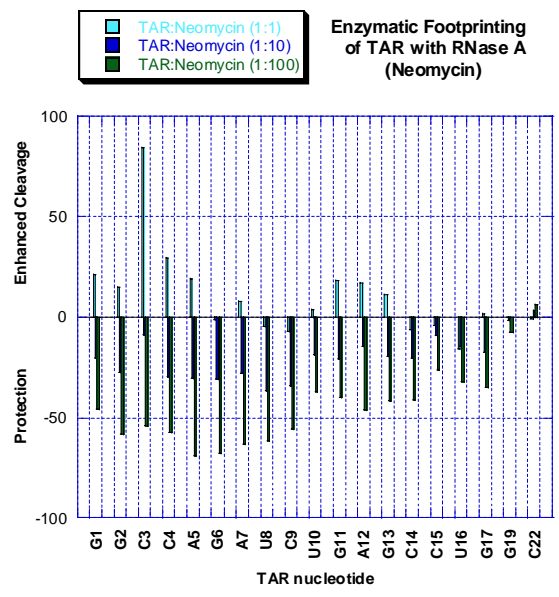

Figure S7

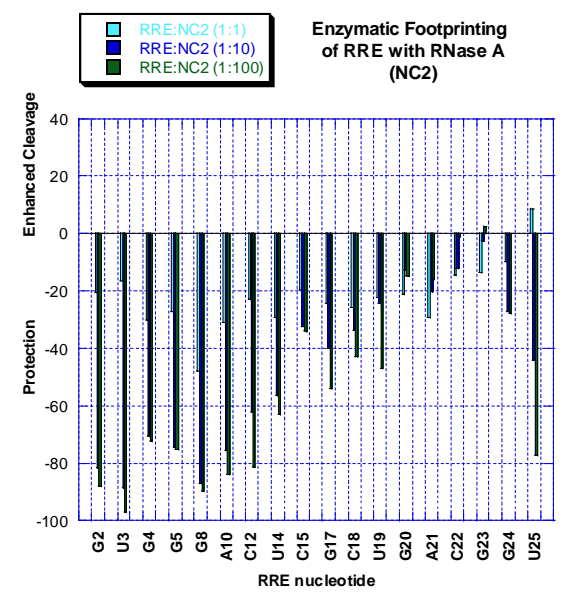

Figure S9

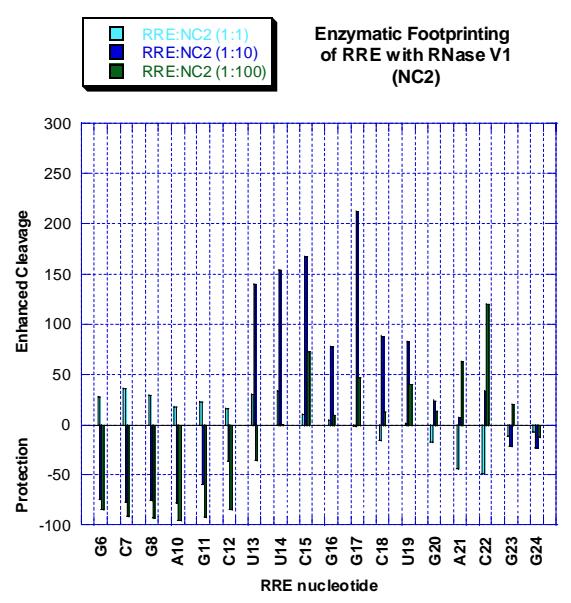

Figure S11

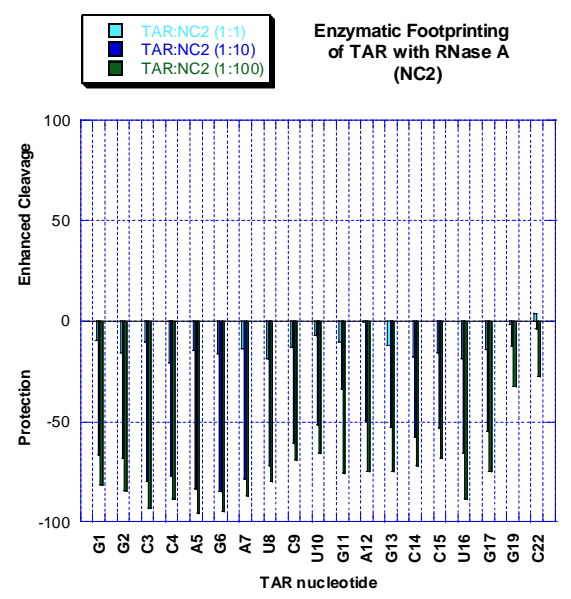


Figure S12

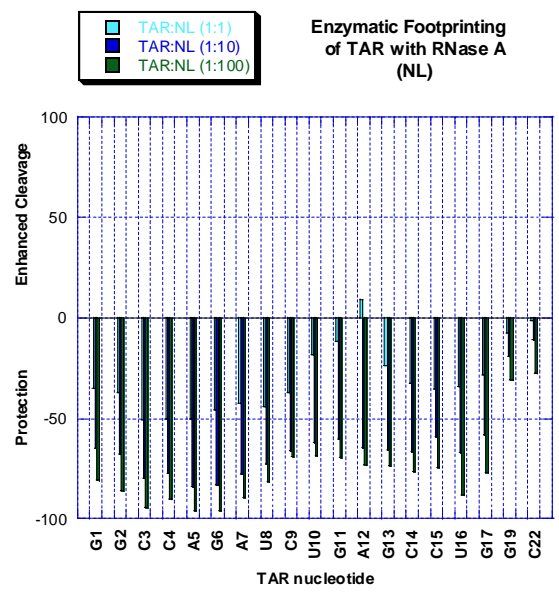

Figure S14

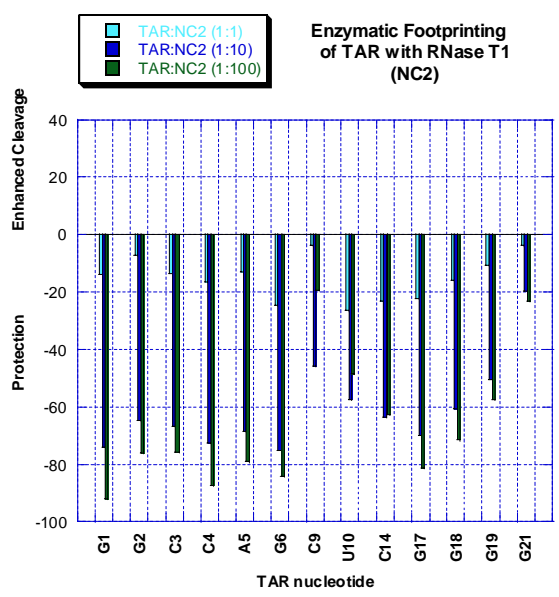

Figure S13

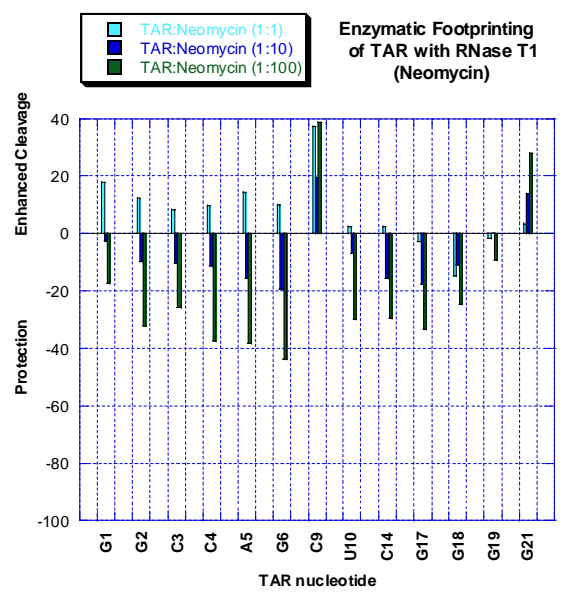

Figure S15

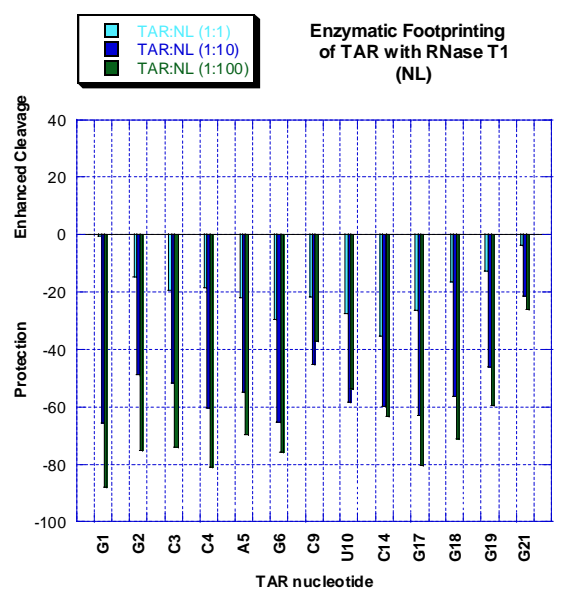

